\title{
Disaggregated Analysis: The Key to Understanding Wellbeing in Kenya in the Context of Food Price Volatility
}

\author{
Nick Chisholm*
}

\begin{abstract}
This article provides a national-level picture of food security and wellbeing in Kenya, focusing on the situation before the 2008 food price crisis, and the period after 2008. The extent and impact of food price changes differ spatially, and households have different ways of trying to respond. The major food price shocks in 2008 and 2011 impacted negatively on wellbeing, but even after 2011 prices continued to rise in most areas. Seasonal price movements also have adverse effects for resource-poor households. Food price rises have a particularly negative impact on the poorest households. Urban slum dwellers are vulnerable given their dependence on market purchases to meet food needs, but most rural households also have high dependence on market purchases. Current social protection programmes are piecemeal and unreliable. The article concludes with proposals on more effective social protection approaches and agricultural programmes which can address problems linked to food price rises.
\end{abstract}

\section{Introduction}

This article derives from rapid research conducted in Kenya as part of the research project Life in a Time of Food Price Volatility. Its objective is to provide a national-level picture of changes in food security and wellbeing for the period before the major global food price rises in 2008, and the period after 2008. A key message is that disaggregated analysis is a necessity if we are to understand the diversity of livelihood situations and factors that influence wellbeing in Kenya.

There are no directly comparable national data sets for pre- and post-2008. Detailed analysis for the pre-2008 period is available, particularly from the 2005/06 Kenya Integrated Household Budget Survey (KIHBS) conducted by the Kenya National Bureau of Statistics (KNBS 2007). This provides a good baseline for analysing poverty and food security status at that time. However, as pointed out by a number of authors and agencies (e.g. World Bank 2013), there has been no recent repeat survey that would allow accurate national assessment of how poverty and food security have changed. Therefore, assessment of the current situation has to be done using a variety of different sources, which can provide a disaggregated overview of recent trends but without allowing for direct comparison with the pre-2008 period.
The approach adopted here is, therefore, to provide an overview of the pre-2008 situation based on the KIHBS in particular, and then build a picture of changes since 2008 up to 2013, making use of a variety of sources. In following this approach, the diversity of conditions in Kenya quickly becomes apparent, reinforcing the importance of conducting disaggregated analyses.

\section{Poverty, food insecurity and wellbeing pre-2008}

The 2005/06 KIHBS derived income and food poverty lines for urban and rural areas (KNBS 2007). ${ }^{1}$ National absolute poverty stood at 45.9 per cent of the population in 2005/06; this compared with 52.3 per cent in the previous poverty survey, the 1997 Welfare Monitoring Survey. Poverty in rural areas stood at 49.1 per cent (52.9 per cent in 1997), while urban poverty was 33.7 per cent in 2005/06 (49.2 per cent in 1997) (KNBS 2007). On average, therefore, headcount poverty rates declined over the 1997-2005/06 period, although they increased in the Coast and North Eastern Provinces.

Food poverty was 45.8 per cent in 2005/06 (48.3 per cent in 1997). In rural areas food poverty was 47.2 per cent (50.7 per cent in 1997), while in urban areas food poverty was 40.5 per cent $(38.3$ per cent in 1997). It is not clear why urban food poverty rates 


\begin{tabular}{lll}
\hline Province & Overall poverty rate (\%) & Food poverty rate (\%) \\
\hline Central & 30.4 & 31.4 \\
Coast & 69.7 & 63.5 \\
Eastern & 50.9 & 45.2 \\
North Eastern & 73.9 & 66.0 \\
Nyanza & 47.6 & 46.0 \\
Rift Valley & 49.0 & 49.5 \\
Western & 52.2 & 51.1 \\
Total rural & 49.1 & 47.2
\end{tabular}

increased over the time period while overall urban poverty rates declined quite substantially.

There was substantial variation in poverty rates across the country (see Table 1). In rural areas, Central Province clearly had the lowest rates of overall and food poverty, while Coast and North Eastern Provinces had the highest rates. Poverty rates were growing in rural areas of Coast and North Eastern Provinces over successive poverty surveys (KNBS 2007). Poverty rates in Nairobi were significantly lower than in other urban areas.

High poverty rates particularly in the north and northeast of Kenya were, and still are, partly a reflection of their arid/semi-arid nature, which limits agricultural potential, and of their historic neglect (World Bank 2013). Population densities in these areas are relatively low, however, and the highest absolute numbers of poor people were concentrated in areas where land is relatively fertile, including Western Kenya around Lake Victoria, the central highlands, and the coast near Mombasa.

Poverty rates were higher with increasing family size and with age of household head, and lower as education levels increased. Poverty rates were higher for female-headed households (FHHs): 50 per cent for rural FHHs and 46.2 per cent for urban FHHs, compared with 48.8 per cent and 30 per cent respectively for male-headed households.
The impact on poverty and wellbeing of changes in food prices varies depending on the share of food expenditure in total expenditure. The KIHBS found that total expenditure was on average almost 50 per cent higher in urban areas than rural areas. Second, there was a substantial difference in the ratio of food to non-food expenditures between rural and urban areas (the ratios are almost reversed: 62.3 per cent: 37.7 per cent in rural areas, and 39.6 per cent: 60.4 per cent in urban areas). Third, the share of food to non-food expenditures declined as total expenditure (taken as a proxy for income) increased. ${ }^{2}$ The poorest areas in expenditure terms (North Eastern Province) had the highest share of expenditure on food (76.3 per cent), and vice versa (Nairobi, on average the richest area, had an expenditure share of 34.6 per cent on food).

When food prices increased in 2008, the greatest impact was likely to hit households with the highest expenditure shares on food. However, impact also varies depending on whether households are net consumers or net producers of food; and the picture needs to be further disaggregated to take into account large income inequalities, including in Nairobi. Although there is a clear difference between rural and urban areas in the proportion of food consumption met from purchases and from own production, even in rural areas over half (53.9 per cent) of all food consumed was purchased from the market. This indicates that rural households' 
consumption patterns were also vulnerable to market fluctuations. In urban areas almost 80 per cent of food consumed was purchased, but when household stocks are included, this rises to 92 per cent.

The proportion of food consumption derived from purchases varies by commodity: the higher the proportion purchased, the greater the influence of food price rises. The key cereal crop and source of dietary energy is maize. In rural areas the percentage share of maize consumption purchased varied from a high of 58.7 per cent in North Eastern Province to a low of 40.8 per cent in Nyanza. Beans are a key source of protein in Kenyan diets: the percentage share of bean consumption from purchases varied from a high of 65.3 per cent in Coast to a low of 40.5 per cent in Nyanza. Another key source of protein and fat is milk: the percentage share of milk consumption from purchases varied from a high of 68.4 per cent in North Eastern Province to a low of 29.7 per cent in Rift Valley Province.

Kenya has high levels of income inequality, particularly in urban areas, and therefore broad province-level or urban centre-level data do not provide a complete picture of the extent to which different sectors of the population are vulnerable to food price rises. At the time, the Gini coefficient of total rural expenditure per adult equivalent was 0.38 , while the urban coefficient was $0.447^{3}$ (KNBS 2007). Average per adult equivalent expenditures among the bottom 10 per cent of households were KSh 466 and KSh 1,110 in rural and urban areas respectively, compared with expenditures for the top 10 per cent of KSh 5,741 and KSh 22,823 in rural and urban areas, respectively: in urban areas, therefore, per adult equivalent expenditures of the top 10 per cent were 20 times greater than those of the bottom 10 per cent (World Bank 2013).

A more disaggregated analysis of food insecurity and food poverty based on the KIHBS was developed in KNBS (2008), which used Food and Agriculture Organization (FAO) measures of dietary adequacy to assess food availability for different sections of the population. Overall, 51 per cent of the population had food consumption levels below the minimum dietary energy requirement (MDER): ${ }^{4}$ almost all (99 per cent) of the bottom quintile of the population fell below the minimum level, compared to less than 1 per cent of the top quintile (KNBS 2008). The depth of hunger was considerable: the average dietary intake of those below the MDER threshold was only $1,261 \mathrm{kcal} /$ person. There were again considerable spatial differences: 57 per cent of the rural population had food consumption levels below the MDER, compared with 39 per cent of the urban population (15 per cent in Nairobi).

Higher-income provinces spent more on food per capita than poorer provinces, but less as a proportion of total expenditure. As household income increases, the proportion of income spent on food tends to decline (an income elasticity of less than one) and the quality and diversity of foods consumed tends to increase. In terms of dietary energy, cereals are generally the cheapest sources of calorific intake and are therefore favoured particularly by poorer people: therefore, increases in cereal prices disproportionately affect poorer households. KNBS (2008) provides data on this issue. Daily average dietary energy consumption was $1,800 \mathrm{kcal} /$ person, ranging from $918 \mathrm{kcal}$ for people in the lowest income decile, to $3,330 \mathrm{kcal}$ for people in the top income decile. Since richer households spend proportionately more on higher quality, more expensive foods, it cost on average KSh 34.50 for an average household in the top quintile to acquire 1,000kcal, compared with a cost of KSh 15.90 for an average household in the lowest quintile (KNBS 2008). The cost of acquiring 1,000kcal was KSh 42 in Nairobi, compared with KSh 17 in Eastern Province (the lowest amount).

\section{Food availability and price trends pre- and post-2008}

Food availability is determined primarily by domestic production and the balance of imports and exports, supplemented by food aid in foodinsecure areas. ${ }^{5}$ Food prices are closely linked to availability. Maize is the predominant staple crop for most Kenyans, and the availability and price of maize are key determinants of food security status. Maize production has fluctuated in recent years, determined predominantly by the incidence and distribution of rainfall. There was a substantial production shortfall in 2008, which was also linked to the disruption resulting from the 2007 postelection violence. Production levels were also low in 2009, but increased during the period 2010-12. Wholesale prices tended to fluctuate in line with production levels, i.e. increased production resulted in lower average wholesale prices and vice versa.

Figure 1 shows trends in maize production and consumption between 2004 and 2013. With the exception of 2005 and 2006, estimated consumption exceeded production in all years, resulting in a need for imports, particularly in 2008 and 2009. 


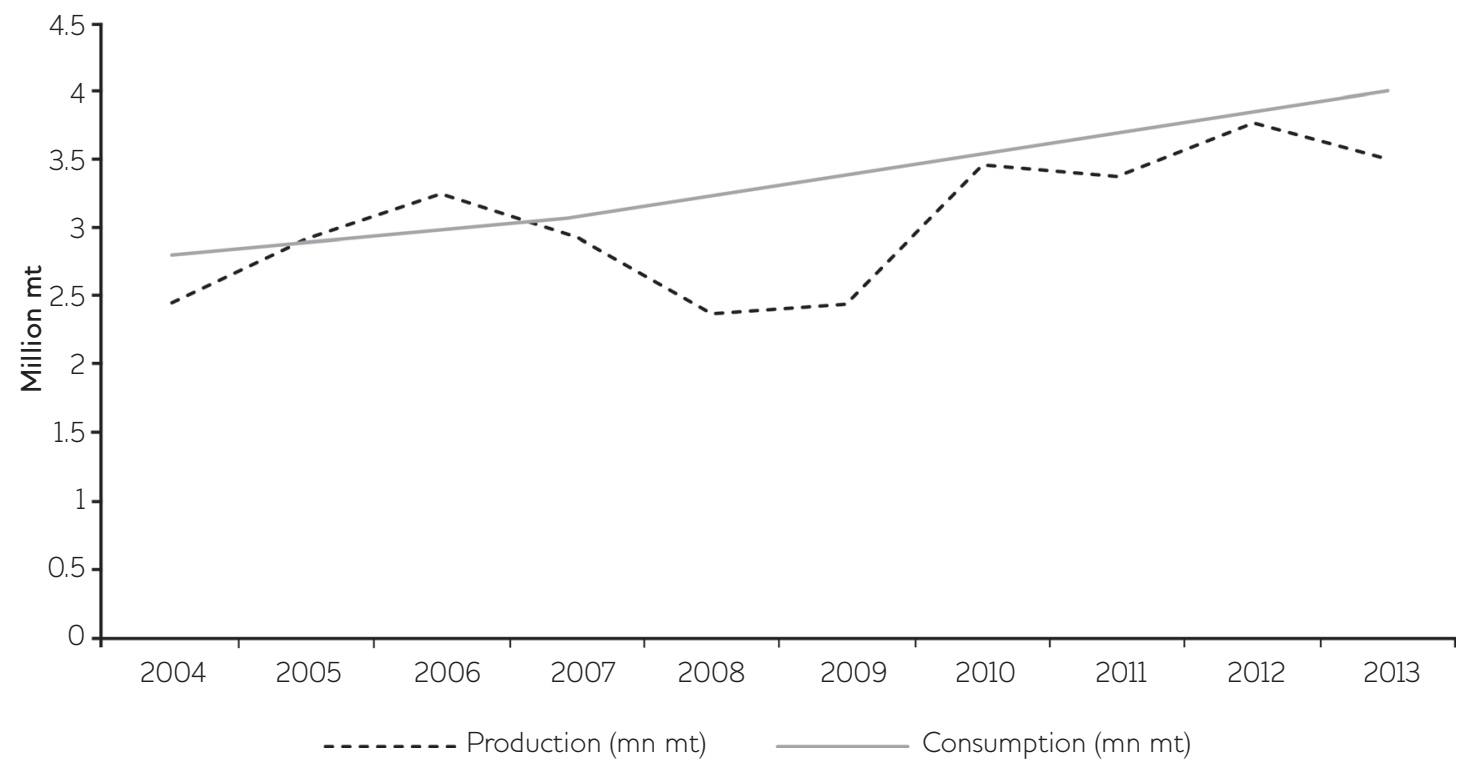

Source Ministry of Agriculture (2007, 2009, 2011, 2013); KNBS (2014). Consumption data for 2009-12 calculated by linear extrapolation from 2008 and 2013 data.

Figure 2 shows trends in maize wholesale prices over the period 2006-14, for Eldoret (a surplusproducing area), Mombasa (a major consuming city and importer) and Nairobi (the main urban consuming area). There is relatively little variation in prices between the three areas. Prices started to rise considerably in 2008, in line with the increase in global prices, but by far the biggest rise was during the severe drought period of 2011: between January and July 2011 prices almost quadrupled

Figure 2 Maize wholesale prices, 2006-14, Eldoret, Mombasa and Nairobi (KSh/kg)

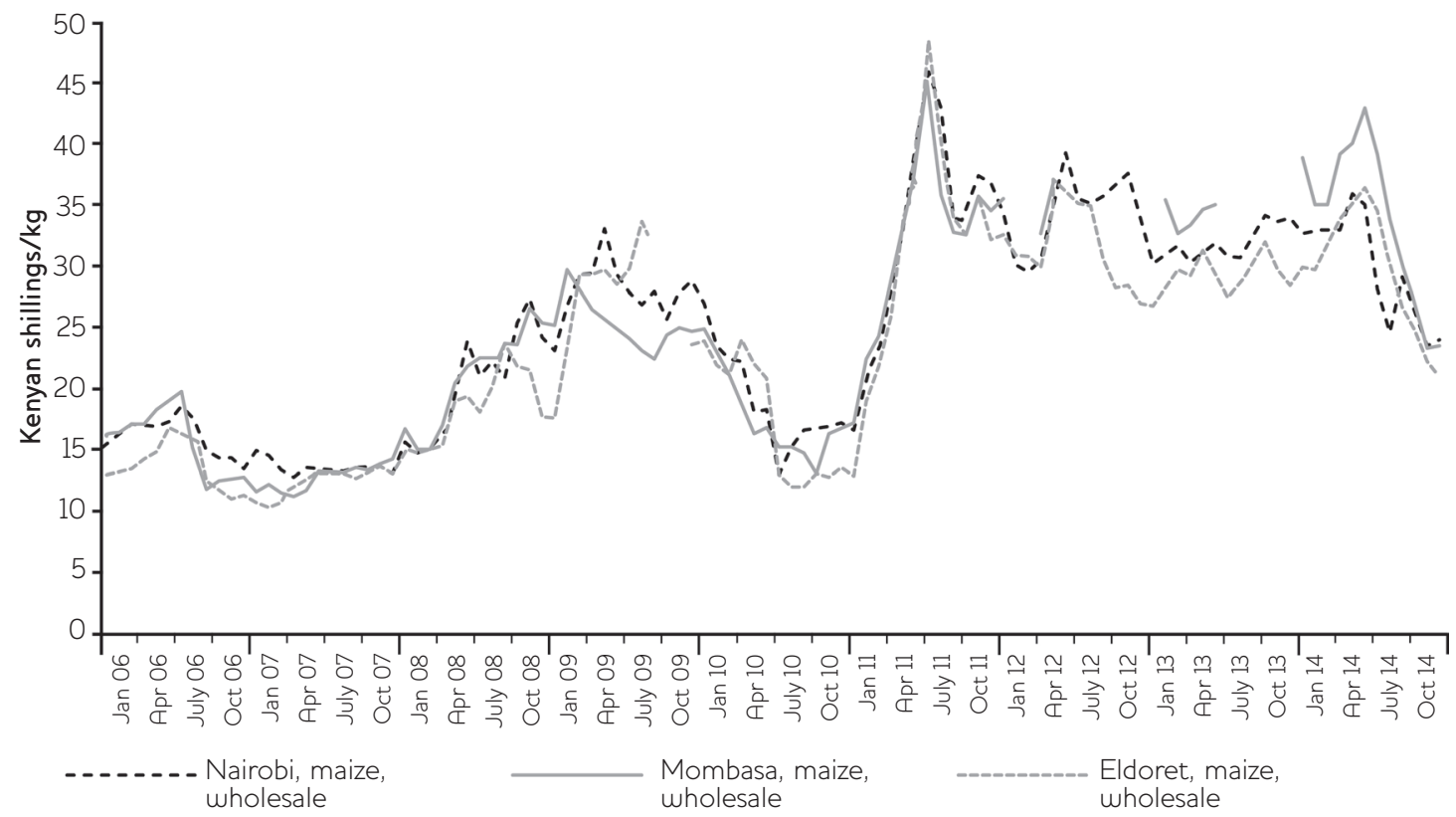


Table 2 Food and overall Consumer Price Index (CPI) for Nairobi income groups, 2011-12 (base February 2009=100)

\begin{tabular}{l|cc|cc|cc}
\hline & \multicolumn{2}{|c|}{ Lower-income group } & \multicolumn{2}{c|}{ Middle-income group } & \multicolumn{2}{c}{ Upper-income group } \\
\hline & Food CPI & Overall CPI & Food CPI & Overall CPI & Food CPI & Overall CPI \\
\hline 2011 & 134.03 & 123.63 & 122.83 & 113.87 & 115.90 & 117.87 \\
2012 & 146.11 & 135.35 & 135.75 & 122.70 & 126.30 & 124.73 \\
\hline
\end{tabular}

Source KNBS (2013).

in Eldoret, and almost tripled in Mombasa and Nairobi, although they later partially fell back. ${ }^{6}$ Over the entire period from January 2006 to mid-2014, prices rose almost threefold in Eldoret, and more than doubled in Mombasa and Nairobi. From the perspective of low-income households, steadily rising prices threaten their livelihoods as much as or more than price volatility per se, since the cost of food over the year may be higher when prices continue to rise.

Retail price trends generally mirror trends in wholesale prices: retail prices of many food commodities doubled over the period 2006-12; and on average most retail prices were higher in 2012 than in 2011 even though peak prices were reached in mid-2011. Overall inflation ${ }^{7}$ and food price inflation rates were lower in 2012 than 2011, but increased again in 2013: the overall inflation rate between December 2012 and December 2013 was 7.15 per cent, and food price inflation was 10.41 per cent over the same time period (KNBS 2013). The imposition of VAT on many essential food items in September 2013 was one of the contributory factors behind this increase in inflation. ${ }^{8}$

The impact of food price increases on households varies with income and other factors. Low-income households spend proportionately more of their (limited) income on food than better-off households, and their diet tends to be less varied. Low-income households in urban areas are particularly vulnerable to increases in the price of staple foods. Data for 2012 (see Table 2) showed that, compared with a base period of February 2009, food prices had increased more rapidly for low-income households in Nairobi than for other groups.

Qualitative research conducted in Kenya as part of the Life in a Time of Food Price Volatility project found that poor households have limited diets and in many cases cope with poverty and higher prices by restricting consumption. Bread and meat are regarded as luxury items, which are rarely consumed. Ugali (maize porridge) and vegetables are the staple diet for most households. A number of households skip breakfast or lunch (Gatimu 2014). The research also pointed to the importance of other essential non-food costs: particularly in the Nairobi slum area of Mukuru, rent, water and toilet facilities are essential costs which were also on the rise.

\section{Disaggregated analysis of changes in food security and wellbeing post-2008}

Kenya has very diverse agro-ecological and livelihood conditions, therefore disaggregated analyses are a necessity to fully understand trends in wellbeing and to identify and design appropriate interventions. This section provides disaggregated analysis based on livelihood zones, as well as synthesising specific analyses from informal settlements in Nairobi.

For food security assessments, 24 livelihood zones have been identified in six major categories: pastoral, agro-pastoral, marginal agricultural, urban, high potential mixed farming, and high potential cereal and dairy (FEWS NET 2013). These zones have different livelihood systems, varied crop and livestock mixes, variations in the extent to which they depend on agriculture or off-farm/non-farm activities to meet their livelihood needs; and therefore differences in the extent and ways in which they are affected by changes in food prices. The most food-insecure areas generally fall within the pastoral, agro-pastoral and marginal agricultural livelihood zones, which cover about 80 per cent of Kenya's land area, but where only about 20 per cent of the population live (KFSSG 2014; FEWS NET 2013). Out of 47 counties created in Kenya under the recent devolution programme, 23 counties fall within these food-insecure livelihood zones: these counties comprise the arid and semi-arid lands (ASALs) which are the focus of most food security activities, 


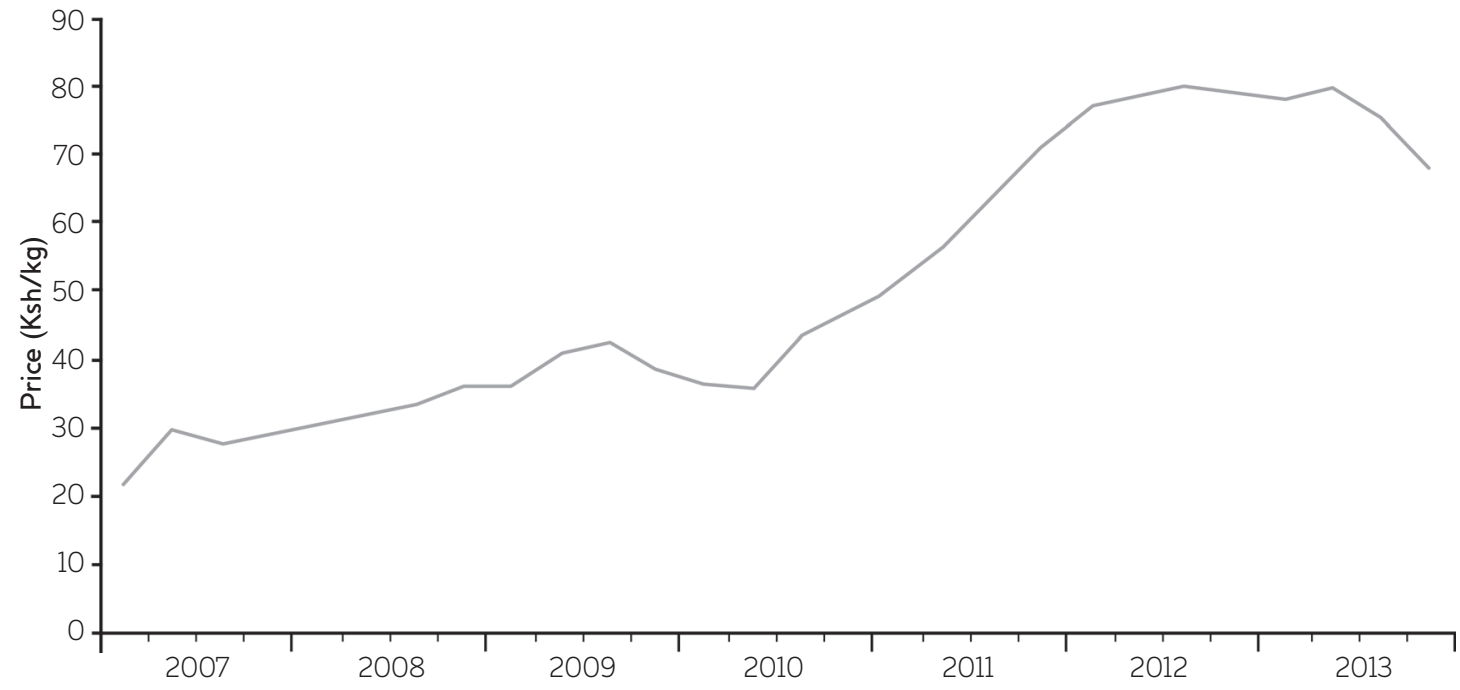

Source KFSSG (2014) and NDMA (2013b).

and fall within the mandate of the National Drought Management Authority (NDMA).

\subsection{Food-insecure counties 4.1.1 Pastoral zone}

In the pastoral zone, price and food security data were analysed for Turkana and Mandera Counties. Both counties have poverty rates above 85 per cent (KNBS 2014). Turkana County in particular is a predominantly pastoralist area with very limited cereal production. Given the livelihood system, the price of cereals and the terms of trade between cereals and livestock are critical to food security status. Prices jumped significantly in 2008 and again in 2011. On average, prices continued to rise during 2012 and 2013: average prices in 2013 were 31 per cent above average levels in 2011. In nominal terms, average prices in 2013 were 168 per cent above those in 2007. There was no obvious seasonal trend in prices; this is an indication of the limited maize production in the county and the effect of other factors such as high transport and other trader-related costs.

Figure 4 Maize/goat ratio (kg maize per medium-sized goat), Mandera County, 2007-13

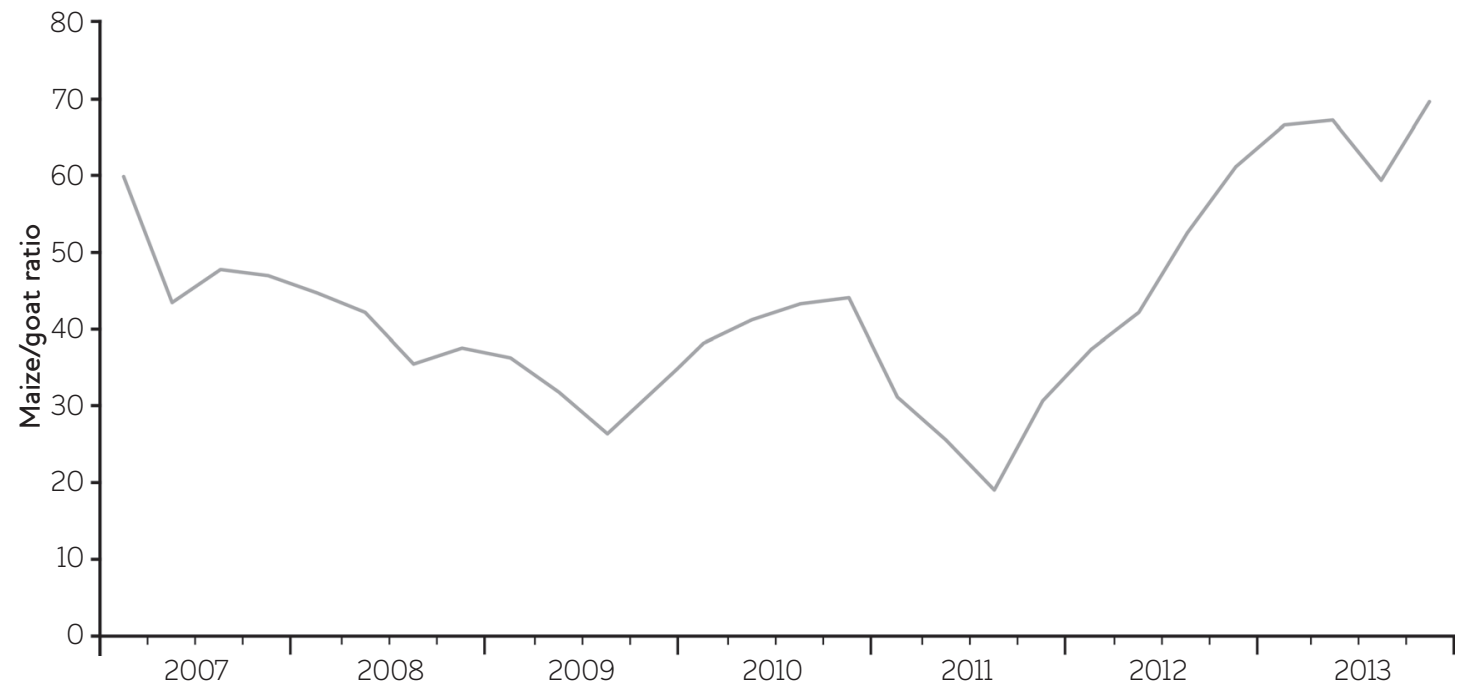

Source Based on KFSSG (2014) and NDMA (2013b). 
Table 3 Turkana and Mandera Counties: percentage of children under age five at risk of undernutrition, (MUAC <135mm), ${ }^{9} 2007-13$

\begin{tabular}{lcc}
\hline Year & Turkana & Mandera \\
\hline 2007 & 15.91 & 23.21 \\
2008 & 20.57 & 19.39 \\
2009 & 25.64 & 18.15 \\
2010 & 20.60 & 18.17 \\
2011 & 25.81 & 26.60 \\
2012 & 18.54 & 27.34 \\
\hline
\end{tabular}

Source KFSSG (2014) and NDMA (2013b and c).

Mandera County combines pastoral, agropastoral and farming (including irrigated farming) livelihoods. Retail maize prices in Mandera County followed a similar trend to Turkana over the period 2007-13: prices increased substantially and were on average 177 per cent higher in 2013 than in 2007 in nominal terms. Although prices jumped by about 50 per cent in 2011 compared to 2010, they then jumped again in 2012, continuing at high levels until mid-2013 before partially falling back (see Figure 3).
The impact of such price rises on livelihoods depends largely on the extent to which incomes also change. In a pastoralist economy, the terms of trade between cereals (maize) and livestock (goats) is one indicator of what is happening to real incomes. In Turkana County there was no clear pattern over 2007-13. In Mandera County the terms of trade clearly deteriorated during 2007-11, recovering in 2012-13 (see Figure 4). The extent to which households actually benefit depends on their livestock holdings:

Figure 5 Retail maize prices, West Pokot County, 2007-13 (KSh/kg)

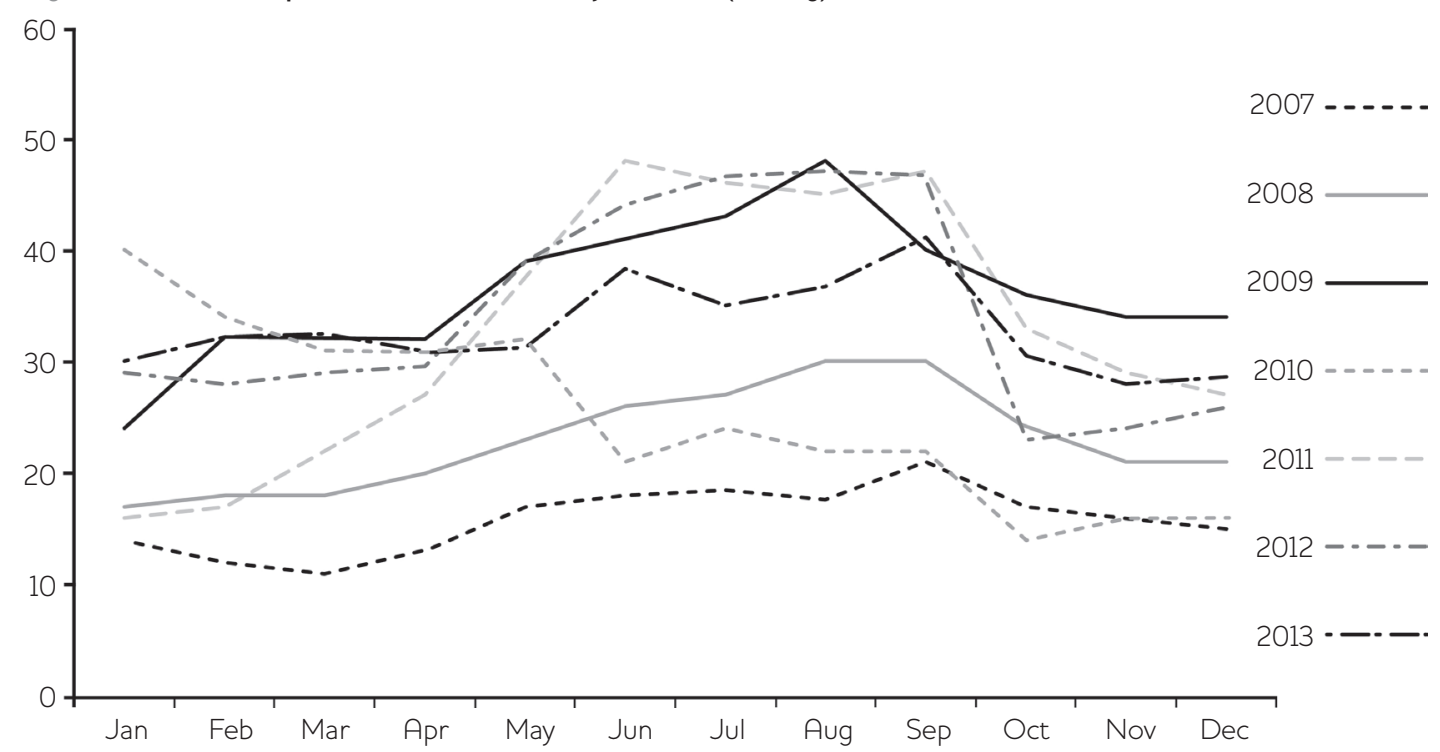

Source KFSSG (2014) and NDMA (2013d). 
households who lack such assets (poorer households) will be most affected by rising maize prices.

Anthropometric data provide some evidence on food security status. Table 3 provides indicators of child undernutrition. In both counties the risk of child undernutrition increased markedly in 2011, but over the whole period there is no clear trend. There is also no obvious relationship between trends in maize prices and levels of child undernutrition; however, the latter is linked to food availability, which is likely to be reflected indirectly in food prices.

\subsubsection{Agro-pastoral zone}

The agro-pastoral livelihood cluster is located in the southwest of Kenya and is characterised by varying combinations of mixed farming, pastoralism, agropastoralism and off-farm activities. On average, livestock production provides about 50 per cent of household income compared with crop production (31 per cent) and off-farm activities (19 per cent). About 60 per cent of food is obtained from market purchases (FEWS NET 2013). West Pokot County was selected for further analysis in this zone.

Prices rose substantially in 2009, and again in 2011 and 2012. There is a clear pattern of within-year variation, where prices reach a peak around JulySeptember and fall back as the long rains harvest takes place (see Figure 5). This pattern will clearly impact on food-insecure households whose stocks are depleted by the time prices rise. The seasonal variation also highlights the importance of other income sources. The main source of income in the county is livestock sales, comprising on average over 40 per cent of all income (NDMA 2013d).

Child undernutrition rates (measured by MUAC) are lower than in the pastoral areas (generally below 10 per cent), but stunting rates appear to be very high. Data from sample sites indicate a stunting rate of 43.2 per cent in 2012 and 46.6 per cent in 2013 (UNICEF 2014). High stunting rates combined with relatively low rates of wasting suggest that health and/or care-related factors may be influencing nutritional status in this area.

\subsubsection{Coastal marginal agricultural zone}

The coastal marginal agricultural livelihood cluster is characterised by mixed farming, generally low agricultural productivity, and relatively high dependence on off-farm income sources. Price and food security trends were analysed in Kilifi County (a bi-modal production area). Unlike the counties discussed above, maize prices peaked in 2011 (July) and then partially fell back; however, average prices in 2013 were still twice those in 2007 in nominal terms. Within-year maize price movements are influenced by local harvest conditions to some extent, rising between the harvest periods.

Data on child undernutrition indicate average annual rates mostly below 10 per cent. Generally, rates are highest during the months before the short rains harvest, when food stocks are likely to be low. Trends in undernutrition are also likely to be linked to a household's capacity to buy food on the market, which in turn depends largely on its sources of income. Generally in Kilifi County, about 50 per cent of income is derived from casual labour, and a relatively high percentage (about $15-20$ per cent) is derived from selling charcoal (NDMA 2013a). Wage rates fluctuate according to labour supply and demand, but the lowest wage rates occur around October-December, shortly before undernutrition rates also start to rise.

The trends discussed above indicate that, for most food-insecure parts of rural Kenya, maize prices have been almost continuously on the rise since at least 2007. Resource-poor rural households in particular are highly vulnerable to such price changes, both within and between years, but the specific impact, and their capacity to cope, varies depending on their livelihood situation.

\subsection{Food insecurity in Nairobi's informal settlements}

Nairobi is by far the largest centre in Kenya with a population of about 3 million in 2009 and a poverty rate of about 22 per cent (KNBS 2014). About 60 per cent of Nairobi's population, and most of the poor, live in informal settlements.

Given that urban populations obtain almost all their food needs from the market, and that poor people spend a higher proportion of their (lower) income on food than other income groups, it can be expected that increasing food prices will have a disproportionate effect on the poor. Since poor people also spend proportionately more on staple foods than other income groups, if prices of staples are rising at a faster rate than prices of other food items, they will again be affected more than other groups.

A number of surveys of household wellbeing have been conducted in Nairobi's informal settlements; many of them make use of longitudinal surveys undertaken by the African Population and Health Research Centre (APHRG). Faye et al. (2011), 
analysing data from the APHRC surveys conducted during 2006-08 in Korogocho and Viwandani, ${ }^{10}$ found that 79.4 per cent of households were food insecure: 88.7 per cent of households in Korogocho and 66.1 per cent of households in Viwandani. Between 2006 and 2008 conditions had deteriorated: in 2006, 36 per cent of sample households in Korogocho stated that they did not have enough to eat, but by 2008 this had increased to 55 per cent. The equivalent figures for Viwandani were 24 per cent and 41 per cent.

Schofield et al. (2013) analysed data from the Nairobi Urban Health and Demographic Surveillance System (NUHDSS) for three time periods: 'pre-emergency' (January-December 2007), 'emergency' (January 2008-June 2009) and 'post-emergency' (July 2009-October 2010). ${ }^{11}$ Household total expenditures and food expenditures increased in the emergency and post-emergency periods, a necessity in the context of food price increases. Expenditures on food averaged 57 per cent of total expenditures across the three periods. During the period, food insecurity, as measured by a food security index, increased: the proportion of households classified in the poorest category based on the food security index increased from 31.6 per cent in the pre-emergency phase, to 34.2 per cent in the emergency phase and 35.1 per cent in the post-emergency phase (Schofield et al. 2013). Moving to 2011 data, Schofield et al. (2013) found a high proportion of households were severely food insecure, particularly in Korogocho, where food insecurity rates ranged from $60-70$ per cent over the four survey rounds conducted in 2011, compared with 30-40 per cent in Viwandani. Over 70 per cent of households engaged in at least one negative coping strategy over the month preceding each of these rounds as a means of making ends meet: such coping strategies include 'removing a child from school, reducing food intake, stealing, sending family members away or begging' (ibid.).

Amendah, Buigut and Mohamed (2014) analysed data collected under the Indicator Development for Surveillance of Urban Emergencies (IDSUE) project for 2012. ${ }^{12}$ They estimated average monthly household income of KSh 11,274, and average monthly expenditure of KSh 13,957. Food expenditures comprised KSh 5,892: 52 per cent of average household income, and 42 per cent of average expenditure. The next most significant expenditures were on education (13 per cent and 10 per cent of income and expenditure, respectively), and rent (12 per cent and 9 per cent).
However, these average data hide substantial income and expenditure differences within and between slum areas, and therefore do not fully convey the impact of food price increases on the poorest. Kagima (2014) presents data from the 2012-13 IDSUE surveys, showing that the lowest quintile of households spend almost all their income on food. Median monthly household income for the bottom quintile is estimated at only KSh 2,400 in Korogocho, compared with KSh 4,800 in Mukuru and Viwandani; the equivalent income figures for the top quintile are KSh 15,000, KSh 22,000 and KSh 20,000, respectively.

Female-headed households comprise a relatively high percentage of households in the informal settlements, reaching about 40 per cent in the bottom quintile of households in the five IDSUE slum areas (three in Nairobi, two in Kisumu). They also make up a high percentage of breadwinners: about 50 per cent in the bottom quintile of households.

\section{Discussion}

A number of key points on food prices and wellbeing emerge from this disaggregated analysis.

First, it is clear that both continually rising food prices (trends) and volatility in prices (shocks) affect wellbeing, particularly of poor households.

There is a clear trend of rising food prices for most of the period. The most substantial price rises were in 2011. Whereas the increases in food prices in 2008 were linked to international trends, in 2011 prices were more influenced by the serious drought conditions in the Horn of Africa. Generally, prices of key food commodities, particularly maize, are strongly influenced by local production and trade conditions.

There was considerable food price volatility in 2008 and, particularly, in 2011, but it can be argued that food price volatility per se is less important, in terms of households' purchasing power, than what happens to average prices over the year. ${ }^{13}$ For example, although the peak (in nominal terms) of maize wholesale prices was reached in July 2011, wholesale prices averaged over the whole year were higher in 2012 than in 2011. Average retail prices of most basic food items were also higher in 2012 than in 2011 .

Second, seasonal price trends are important, and affect food security as well as nutritional status. In rural areas these price trends are linked with food 
availability as well as factors such as distribution costs (which are also connected with other factors such as the degree of trader influence on food distribution systems: the role of traders in the food grain market is discussed, for example, in Musembi and Scott-Villiers 2015). Seasonal patterns and impacts on wellbeing vary depending on the livelihood zone: in broad terms, resource-poor households are less likely to benefit from higher prices since they are net consumers. This is where price volatility can have a specific impact: the greater the within-year price variation, the greater the probable negative impact on resource-poor households who have to sell when prices are low (harvest time) and buy back when prices are high (when household food stocks are low). However, this impact also depends on the extent to which households have alternative sources of income ${ }^{14}$ and the relative prices of such sources.

Third, it is not possible to come to a definitive conclusion about overall trends in rural food security, poverty and wellbeing, since they are so varied. Even though maize prices have risen substantially since the pre-2008 period, child undernutrition rates have varied, peaking in some counties in 2011 and then declining. The available data tend to suggest continued high levels of chronic vulnerability, punctuated by crises.

Fourth, some analyses of living conditions in informal settlements in Nairobi point to substantial variations in incomes of households: incomes of the bottom quintile are very low. Kagima (2014) provides evidence of clustering of income cohorts in particular neighbourhoods within settlements. In the context of rising prices of food and other basic commodities, and data showing such prices increasing at a faster rate for lower income than for other households (see Table 2), a high proportion of the poorest households have to resort to 'negative' coping strategies such as taking children out of school, reducing food intake, or begging.

Overall, most poor rural and urban households in Kenya are negatively affected by rising food prices, and this is the scenario they have faced for the last few years. However, livelihood conditions are diverse and therefore the effects of food price rises are not uniform. The causes of such price changes also vary. These points underline the importance in the context of Kenya of undertaking disaggregated analyses of food security and wellbeing across time and space, to provide better information for policy and programme development.

\section{Conclusions}

This article outlines and examines some broad trends in food prices, food production and other key indicators of food security in Kenya. It is clear that food price rises have been the norm for the majority of the population in the last few years; that such price rises are detrimental for most people, particularly for the poor; and that domestic factors have a substantial influence on what happens to prices.

Shortfalls in maize production create conditions where prices are likely to increase, but the extent of such increases is also linked with the maize marketing environment, including the role of powerful traders. Agricultural programmes that significantly boost maize production and/or a more liberalised regional trade environment could provide some of the solution to rising prices, as could a properly resourced and well-managed strategic grain reserve.

Social protection policy and programmes have been piecemeal and narrowly targeted until now; in rural areas there remains a predominant focus on addressing emergency food needs and acute undernutrition. There are strong grounds for developing a more integrated and comprehensive social protection policy, which could combine protection with support to increase production. Such an expanded and reformed social protection policy needs to be disaggregated and agile, capable of responding to the realities of when households are most under pressure from rising prices and/or falling incomes. Social protection programmes also need to be greatly expanded in urban slum areas, where poverty and food insecurity reach very high levels among the poorest households.

There is a need for a better understanding of factors affecting food price dynamics and broader livelihoods issues. In part, this involves expanded and systematic data collection, such as the in-depth longitudinal data collection undertaken by the Life in a Time of Food Price Volatility project and through the NUHDSS in Nairobi informal settlements, as well as the monthly reports of the NDMA in the ASAL counties. There is also an urgent need to undertake a repeat national-level survey of the KIHBS to provide comparable national data on trends in poverty and food security status.

The Life in a Time of Food Price Volatility project has emphasised the importance in policy-relevant research of utilising and integrating both qualitative and quantitative data. However, there are some 
important livelihoods issues which require more research. These include detailed information on changes in work, wages, and earnings during the year (i.e. to what extent, and how, do people make up for the loss of real incomes associated with rising prices, and are there any trade-offs involved, e.g. in relation to care of children); understanding the seasonal dynamics and impacts of price changes, particularly in rural areas (i.e. when do resourcepoor farmers sell food and when do they purchase, and what are the prevailing prices in each time period); and understanding some of the forces and actors involved in price-setting (e.g. the role of traders). A greater understanding of these issues can contribute to improved design of development interventions aimed at enhancing the resilience of

\section{Notes}

* The author is a Senior Lecturer in International Development in the Department of Food Business and Development, University College Cork, Ireland.

1 Poverty lines were derived from the survey results based on the cost of meeting a basic needs basket. In adult equivalent terms, the monthly cost for a rural household was KSh 1,562, and for an urban household it was KSh 2,913 (KNBS 2007; World Bank 2013). The equivalent food poverty lines were KSh 988 and KSh 1,474 for rural and urban households respectively, where the food poverty line was estimated as the cost of consuming 2,250kcal per adult equivalent per day.

2 The correlation coefficient for total expenditure against share of expenditure on food is -0.94 .

3 The Gini coefficient is a measure of income inequality ranging between zero and one: the higher the value of the coefficient, the higher the level of inequality.

4 The MDER was taken as the minimum dietary energy needed to maintain body weight and perform sedentary light physical activity, taking into account age and sex. The national MDER was calculated at 1,683kcal/person/day (KNBS 2008). It should be noted that the published FAO MDER for Kenya calculated for the period 2006-08 was $1,760 \mathrm{kcal} /$ person/day.

5 The Government of Kenya, through the National Cereals and Produce Board (NCPB), also maintains a Strategic Grain Reserve, but this has rarely been kept at adequate levels. The current target is to maintain a reserve of 8 million $90 \mathrm{~kg}$ bags of maize, equivalent to about two months' consumption.

6 The coefficient of variation in maize food prices was much greater in 2011 than in 2008. poor households in the face of rising and volatile food prices.

This article has not focused in detail on the range of relevant government policies and programmes currently being developed and implemented in Kenya, nor on issues related to the political economy of the food system, which clearly are important in an overall assessment of the extent to which Kenyan citizens can realise a right to food. Even in the absence of such a political economy perspective, it is clear that there are many basic socioeconomic and structural factors that constrain people's ability to meet their food and nutrition security needs, and that require a sustained and enhanced focus of development resources to address them.

7 As measured by the Consumer Price Index (CPI).

8 The introduction of the VAT Act in September 2013 resulted in a direct increase in the price of milk and other food commodities: originally VAT was also to be applied to maize flour, but after protests by many civil society organisations it was zero-rated, and milk was also zero-rated when the law was amended (Gatimu 2014).

9 Mid-upper arm circumference, a measure of acute malnutrition.

10 Korogocho and Viwandani are both slum areas in Nairobi.

11 'Emergency' here refers to the combination of events and shocks which took place around that period, particularly the post-election violence in 2007 and the food price shocks beginning in 2008.

12 The APHRG and Concern Worldwide are implementing the Indicator Development for Surveillance of Urban Emergencies project, to develop early warning indicators for slowonset emergencies in urban areas. This initially started in Korogocho and Viwandani, but has since expanded to two further areas in Nairobi, Mukuru (one of the sites of the qualitative research in the food price volatility project) and Dandora, and two slums in Kisumu city (Amendah et al. 2014).

13 It is possible to envisage a situation of high price volatility where the average price does not change much (if price increases are more or less matched by price decreases over the time period); or a situation of lower volatility where the average price increases more. Other things being equal, household expenditure would be required to increase more in the latter scenario.

14 And food, if they are growing 'traditional' staple crops which can be substituted for maize. 


\section{References}

Amendah, D.; Buigut, S. and Mohamed, S. (2014) 'Coping Strategies among Urban Poor: Evidence from Nairobi, Kenya', PLoS ONE 9.1: e83428

FAO GIEWS (2014) Food Price Series for Kenya, www.fao.org/giews/pricetool (accessed 19 August 2015)

Faye, O.; Baschieri, A.; Falkingham, J. and Muindi, K. (2011) 'Hunger and Food Insecurity in Nairobi's Slums: An Assessment Using IRT Models', fournal of Urban Health: Bulletin of the New York Academy of Medicine 88, Suppl. 2: S235-55

FEWS NET (Famine Early Warning Systems Network) (2013) Kenya Food Security Brief, December, Washington DC: USAID

Gatimu, C. (2014), Life in a Time of Food Price Volatility: Evidence from the Poor and Vulnerable in Mukuru and Lango Baya, Kenya, Joint Agency Research Report, Oxford: Oxfam International

Kagima, B. (2014) '2013 "IDSUE Results"', unpublished presentation, Nairobi: Concern Worldwide

KFSSG (Kenya Food Security Steering Group) (2014) October to December 2013 Short Rains Season Assessment Report, Nairobi: Government of Kenya KNBS (Kenya National Bureau of Statistics) (2014) Economic Survey 2014, Nairobi: Government of Kenya

KNBS (Kenya National Bureau of Statistics) (2013) Statistical Abstract 2013, Nairobi: Government of Kenya

KNBS (Kenya National Bureau of Statistics) (2008) Food Insecurity Assessment in Kenya, Based on Kenya Integrated Household Budget Survey 2005/06, Nairobi: Government of Kenya

KNBS (Kenya National Bureau of Statistics) (2007) Basic Report on Wellbeing in Kenya, Based on Kenya Integrated Household Budget Survey 2005/06, Nairobi: Government of Kenya
Ministry of Agriculture (2013) Economic Review of Agriculture, Nairobi: Ministry of Agriculture

Ministry of Agriculture (2011) Economic Review of Agriculture, Nairobi: Ministry of Agriculture

Ministry of Agriculture (2009) Economic Review of Agriculture, Nairobi: Ministry of Agriculture

Ministry of Agriculture (2007) Economic Review of Agriculture, Nairobi: Ministry of Agriculture

Musembi, C. and Scott-Villiers, P. (2015) Food Riots and Food Rights: The Moral and Political Economy of Accountability for Hunger in Kenya, IDS Working Paper 461, Brighton: IDS

NDMA (National Drought Management Authority) (2013a) Kilifi County Drought Monitoring Early Warning Bulletin, www.ndma.go.ke (accessed 11 August 2015)

NDMA (National Drought Management Authority) (2013b) Mandera County Drought Monitoring Early Warning Bulletin, www.ndma.go.ke (accessed 11 August 2015)

NDMA (National Drought Management Authority) (2013c) Turkana County Drought Monitoring Early Warning Bulletin, www.ndma.go.ke (accessed 11 August 2015)

NDMA (National Drought Management Authority) (2013d) West Pokot County Drought Monitoring Early Warning Bulletin, www.ndma.go.ke_(accessed 11 August 2015)

Schofield, L.; Mohamed, S.; Kimani-Murage, E.; Wekesah, F.; Mberu, B.; Egondi, T.;

Kyobutungi, C. and Ettarh, R. (2013) 'Spotting the Invisible Crisis: Early Warning Indicators in Urban Slums of Nairobi, Kenya', Field Exchange 46: 55

UNICEF (2014) 'Nutrition Data', unpublished, Nairobi: UNICEF

World Bank (2013) Kenya Economic Update: Time to Shift Gears: Accelerating Growth and Poverty Reduction in the New Kenya, June, Edition 8, Washington DC: World Bank 